Article

\title{
Induction of Antibacterial Metabolites by Co-Cultivation of Two Red-Sea-Sponge-Associated Actinomycetes Micromonospora sp. UR56 and Actinokinespora sp. EG49
}

\author{
Mohamed S. Hifnawy ${ }^{1,+}$, Hossam M. Hassan ${ }^{2,+} \mathbb{D}$, Rabab Mohammed ${ }^{2}$, Mohamed M. Fouda ${ }^{3}$, \\ Ahmed M. Sayed ${ }^{3}\left(\mathbb{D}\right.$, Ahmed A. Hamed ${ }^{4}\left(\mathbb{D}\right.$, Sameh F. AbouZid ${ }^{2}$, Mostafa E. Rateb ${ }^{5}$, \\ Hani A. Alhadrami ${ }^{6,7, *(D)}$ and Usama Ramadan Abdelmohsen ${ }^{8,9, *(D)}$ \\ 1 Department of Pharmacognosy, Faculty of Pharmacy, Cairo University, 11787 Cairo, Egypt; \\ mhifnawy@hotmail.com \\ 2 Department of Pharmacognosy, Faculty of Pharmacy, Beni-Suef University, 62514 Beni-Suef, Egypt; \\ abuh20050@yahoo.com (H.M.H.); rmwork06@yahoo.com (R.M.); sameh.zaid@pharm.bsu.edu.eg (S.F.A.) \\ 3 Department of Pharmacognosy, Faculty of Pharmacy, Nahda University, 62513 Beni-Suef, Egypt; \\ foudapharma@gmail.com (M.M.F.); ahmed.mohamed.sayed@nub.edu.eg (A.M.S.) \\ 4 Microbial Chemistry Department, National Research Center, 33 El-Buhouth Street, 12622 Giza, Egypt; \\ ahmedshalbio@gmail.com \\ 5 School of Computing, Engineering \& Physical Sciences, University of the West of Scotland, Paisley PA1 2BE, UK; \\ mostafa.rateb@uws.ac.uk \\ 6 Department of Medical Laboratory Technology, Faculty of Applied Medical Sciences, \\ King Abdulaziz University, Jeddah 21589, Saudi Arabia \\ 7 Special Infectious Agent Unit, King Fahd Medical Research Centre, King Abdulaziz University, \\ Jeddah 21589, Saudi Arabia \\ 8 Department of Pharmacognosy, Faculty of Pharmacy, Minia University, 61519 Minia, Egypt \\ 9 Department of Pharmacognosy, Faculty of Pharmacy, Deraya University, Universities Zone, \\ P.O. Box 61111 New Minia City, Egypt \\ * Correspondence: hanialhadrami@kau.edu.sa (H.A.A.); usama.ramadan@mu.edu.eg (U.R.A.) \\ + These authors equally contributed to this work.
}

Received: 27 March 2020; Accepted: 30 April 2020; Published: 5 May 2020

check for updates

\begin{abstract}
Liquid chromatography coupled with high resolution mass spectrometry (LC-HRESMS)-assisted metabolomic profiling of two sponge-associated actinomycetes, Micromonospora sp. UR56 and Actinokineospora sp. EG49, revealed that the co-culture of these two actinomycetes induced the accumulation of metabolites that were not traced in their axenic cultures. Dereplication suggested that phenazine-derived compounds were the main induced metabolites. Hence, following large-scale co-fermentation, the major induced metabolites were isolated and structurally characterized as the already known dimethyl phenazine-1,6-dicarboxylate (1), phenazine-1,6-dicarboxylic acid mono methyl ester (phencomycin; 2), phenazine-1-carboxylic acid (tubermycin; 3), N-(2-hydroxyphenyl)-acetamide (9), and p-anisamide (10). Subsequently, the antibacterial, antibiofilm, and cytotoxic properties of these metabolites (1-3, 9, and 10) were determined in vitro. All the tested compounds except 9 showed high to moderate antibacterial and antibiofilm activities, whereas their cytotoxic effects were modest. Testing against Staphylococcus DNA gyrase-B and pyruvate kinase as possible molecular targets together with binding mode studies showed that compounds 1-3 could exert their bacterial inhibitory activities through the inhibition of both enzymes. Moreover, their structural differences, particularly the substitution at C-1 and C-6, played a crucial role in the determination of their inhibitory spectra and potency. In conclusion, the present study highlighted that microbial co-cultivation is an efficient tool for the discovery of new antimicrobial candidates and indicated phenazines as potential lead compounds for further development as antibiotic scaffold.
\end{abstract}


Keywords: co-cultivation; phenazine; sponge-associated actinomycetes; antibacterial; antibiofilm; DNA gyrase; pyruvate kinase

\section{Introduction}

Natural products derived from marine microbes play a pivotal role in drug discovery and development due to their diverse molecular and chemical scaffolds, which cannot be matched by any synthetic or combinatorial libraries [1]. Marine-sponge-associated actinomycetes have recently been used to produce a multitude of new bioactive compounds with novel molecular scaffolds and potent pharmacological activities such as antibacterial, antifungal, antiparasitic, immunomodulatory, anti-inflammatory, antioxidant, and anticancer activities [2-5]. However, searching for new and promising bioactive secondary metabolites from marine microbes is becoming a serious challenge due to the increasing rate of rediscovery of known secondary metabolites [6,7]. On the other hand, genomic work has revealed that definite groups of bacteria and fungi have huge numbers of silent biosynthetic gene clusters (BGCs) that encode for secondary metabolites that are not traced under normal laboratory conditions [8,9]. Microbial competition for space and nutrition are considered eventual routes for the induction of bioactive metabolites, mainly antimicrobial agents [10]. Several protocols have been used to trigger such cryptic biosynthetic pathways. One of these protocols involves co-cultivation or the so-called mixed fermentation of two or more microorganisms in a single culture flask, which results in the production of antimicrobial secondary metabolites [11-13]. Recently, we reported the production of new antitumor agents, saccharomonosporine A and convolutamydine $\mathrm{F}$, by the co-fermentation of two marine-sponge-associated actinomycetes, Dietzia sp. UR66 and Saccharomonospora sp. UR22, obtained from Callyspongia siphonella [14]. A chlorinated benzophenone pestalone that showed potent antibiotic activity was sourced from the co-cultivation of two marine-associated fungi, $\alpha$-proteobacterium CNJ-328 and Pestalotia sp. CNL-365 [15]. The induction of cryptic pulicatin derivatives that exhibit potent antifungal effects through the microbial co-culture of Pantoea agglomerans with Penicillium citrinum was recently reported [16]. Finally, the induced production of emericellamides A and B obtained from a co-fermentation of the marine-associated fungus Emericella sp. CNL-878 and the marine derived bacterium Salinispora arenicola was reported [17].

Phenazine compounds are heterocyclic nitrogenous compounds that consist of two benzene rings attached through two nitrogen atoms and substituted at different sites of the core ring system. Phenazine derivatives have been found to show a wide range of biological activities, including antibacterial, antiviral, antitumor, antimalarial, and antiparasitic activities $[18,19]$. They have been isolated in large amounts from terrestrial bacteria such as Pseudomonas, Streptomyces, and other genera from marine habitats [20]. The iminophenazine clofazimine is an example of a successful phenazine derivative, having been approved by the FDA for the treatment of leprosy and drug-resistant Mycobacterium tuberculosis strains [21,22]. Another example of a phenazine is bis-(phenazine-1-carboxamide), which acts as a strong cytotoxin and represents an attractive class of anticancer drugs [23]. In an earlier work, we found that Actinokineospora sp. EG49 was able to induce Nocardiopsis sp. RV163 to produce 1,6-dihydroxyphenazine upon co-cultivation [24]. On the other hand, Micromonospora sp. are widespread actinomycetes and prolific producers of diverse antibiotics $[25,26]$. Consequently, we decided to extend our co-cultivation trials on both marine-derived Actinokineospora sp. EG49 and Micromonospora sp. UR56 in order to induce the production of further antibacterial metabolites, which were also found to be of the phenazine class. Based on earlier reports on the biological activities of this class of compounds, we suggested both DNA gyrase B (Gyr-B) and pyruvate kinase (PK) to be the possible molecular targets of their antibacterial activity. The working outline of the present study is illustrated in Figure 1. 


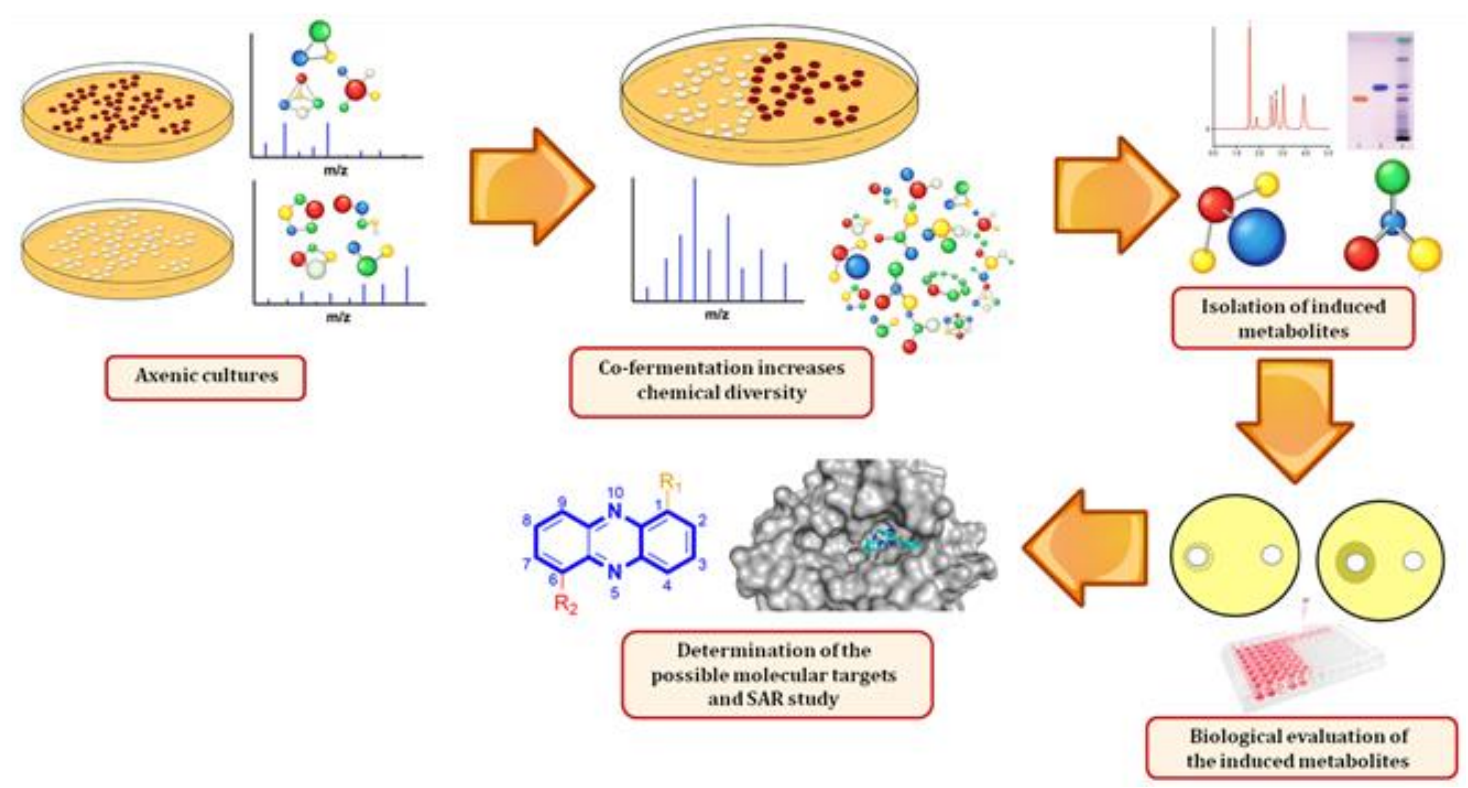

Figure 1. Outline of the procedure used in the present study.

\section{Results and Discussion}

\subsection{Metabolomic Profiles of the Axenic and Co-Culture Extracts}

The chemical profiles of the actinomycetes Micromonospora sp. UR56 and Actinokineospora sp. EG49 were investigated via liquid chromatography coupled with mass spectrometry (LC-HRMS) analysis after their fermentations (axenic and co-fermentation). The metabolomic profile of the co-culture extract displayed the induction of diverse metabolites from different chemical classes compared to those of the two axenic cultures (Figure 2, Supplementary Figure S32, and Supplementary Table S3). Twelve metabolites were putatively identified in the Micromonospora sp. UR56-derived extract, where phenazine derivatives were found to prevail (Figure 2; Figure 3, Supplementary Figure S30). Most of these dereplicated phenazines e.g., phenazine-1-carboxylic acid (3), aestivophoenin c (8), and methyl saphenate (4) have been reported to possess antimicrobial and cytotoxic properties [27]. The remaining identified compounds were found to belong to the $\mathrm{N}$-containing and polyketide classes. Within the axenic Actinokineospora sp. EG49 culture, no phenazine derivatives were traced in the LC-HRMS analysis of the extract. Additionally, its chemical profile revealed poor diversity, with a few identified N-containing and polyketide metabolites (Supplementary Figure S31 and Supplementary Table S2). On the other hand, the mixed fermentation of both actinomycetes induced Micromonospora sp. UR56 to accumulate diverse phenazine derivatives (1-8) (Figure 2). Such induction could be due to environmental competition or chemical defense mechanisms [10]. Based on the metabolomic profiling of the co-culture, the major induced metabolites (1-3, 9, and 10) were targeted and isolated using Sephadex LH20 followed by silica gel column chromatography, and identified using different spectroscopic approaches. Subsequently, they were subjected to antibacterial, antibiofilm, and cytotoxicity testing. 


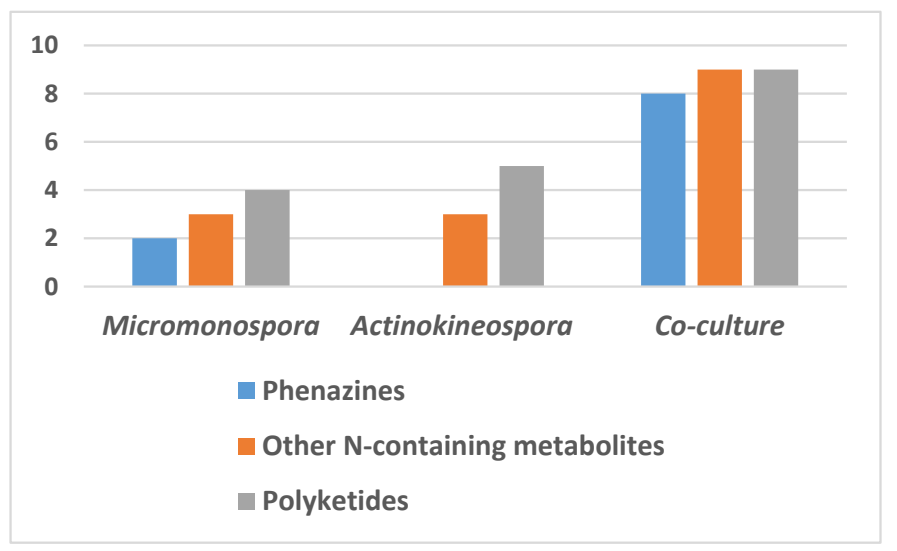

Figure 2. Classes of metabolites produced from Micromonospora sp. UR56 and Actinokineospora sp. EG49 axenic and co-cultures.<smiles>COC(=O)c1cccc2nc3c(C(=O)OC)cccc3nc12</smiles>

(1)<smiles>COC(=O)c1cccc2nc3c(C(=O)O)cccc3nc12</smiles>

(2)<smiles>O=C(O)c1cccc2nc3ccccc3nc12</smiles>

(3)<smiles>CO[C@H](C)c1cccc2nc3c(C(=O)O)cccc3nc12</smiles>

(4)<smiles>O=C(O)c1cccc2nc3c(CO)cccc3nc12</smiles>

(5)<smiles>COc1ccc(CO)c2nc3cccc(C(=O)O)c3nc12</smiles>

(6)<smiles>CC(=O)Nc1ccccc1O</smiles>

(9)<smiles>COc1ccc(COC(=O)CO)c2nc3cccc(C(=O)O)c3nc12</smiles>

(7)<smiles>CC(C)=CCc1cccc2c1Nc1c(C(=O)OC(O)C(O)O)cccc1N2CC=C(C)C</smiles><smiles>COc1ccc(C(N)=O)cc1</smiles>

(10)

Figure 3. Identified phenazine derivatives in the axenic Micromonospora sp. UR56 culture, and after its co-culture with Actinokineospora sp. EG49. 1: dimethyl phenazine-1,6-dicarboxylate, 2: phencomycin, 3: phenazine-1-carboxylic acid, 4: methyl saphenate, 5: 1-hydroxy methyl-6-carboxy phenazine, 6: griseolutic acid, 7: griseolutin A, 8: aestivophoenin C, 9: N-(2-hydroxyphenyl)-acetamide, and 10: $p$-anisamide.

\subsection{Bioactivity Testing}

\subsubsection{Antibacterial Activity}

Based on earlier reports on their antibacterial potential, phenazine-derived compounds have proven to be an interesting chemical scaffold for the development of new antibacterial 
agents [27]. Therefore, all isolated compounds were evaluated against Staphylococcus aureus ATCC9144, Bacillus subtilis ATCC29212, Pseudomonas aeruginosa ATCC27853, and Escherichia coli ATCC25922 (Table 1). Compounds 3 and $\mathbf{1 0}$ displayed potent antibacterial activity against P. aeruginosa with growth inhibition of $94 \%$ and 70\%, respectively, while compounds 1, 2, and 9 showed considerable antibacterial activity against $S$. aureus with growth inhibition of $47 \%, 69 \%$, and $53 \%$, respectively (Table 1). Based on these results together those previously reported [27], we concluded that the phenazine-1-carboxylic acid scaffold is essential for antibacterial activity against Gram-negative bacteria and produces no observable activity towards Gram-positive ones. Although the addition of another carboxylic acid or carboxyl ester at C-6 significantly decreased the inhibitory activity against Gram-negative bacteria, it converted these phenazine derivatives to be active against Gram-positive strains (Figure 4).

Table 1. Growth inhibition \% of 1-3, 9, and $\mathbf{1 0}$ at $15 \mu \mathrm{M}$ against different bacterial strains.

\begin{tabular}{ccccc}
\hline Tested Compounds & Staphylococcus aureus & Bacillus subtilis & Escherichia coli & Pseudomonas aeruginosa \\
\hline $\mathbf{1}$ & $57.19 \pm 1.2$ & $19.61 \pm 1.5$ & $9.93 \pm 1.3$ & $23.41 \pm 1.7$ \\
$\mathbf{2}$ & $68.87 \pm 0.8$ & $32.13 \pm 1.3$ & $11.15 \pm 1.4$ & $23.25 \pm 2.2$ \\
$\mathbf{3}$ & $\mathrm{NA}$ & $1.69 \pm 1.2$ & $24.34 \pm 1.8$ & $94.17 \pm 2.8$ \\
$\mathbf{9}$ & $1.1 \pm 0.9$ & $\mathrm{NA}$ & $\mathrm{NA}$ & $4.74 \pm 1.6$ \\
$\mathbf{1 0}$ & $53.17 \pm 1.2$ & $42.16 \pm 1.9$ & $19.27 \pm 2.5$ & $70.23 \pm 1.1$ \\
Gentamicin & $99.1 \pm 0.7$ & $97 \pm 1.6$ & $99 \pm 0.6$ & $99.7 \pm 0.2$ \\
\hline
\end{tabular}

NA: no activity.

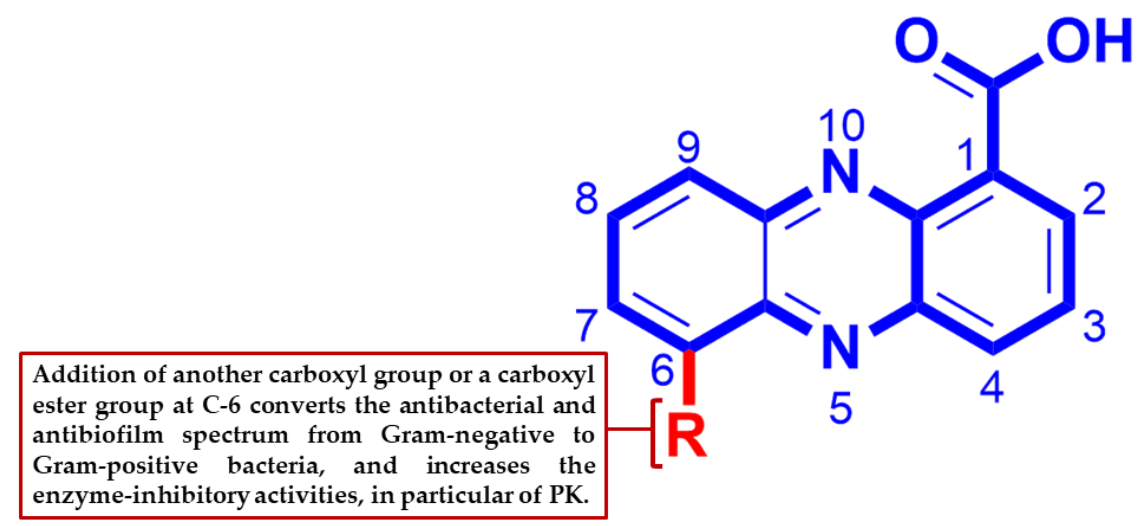

Figure 4. Structure-activity relationship of the induced phenazine derivatives.

\subsubsection{Antibiofilm Activity}

To further evaluate the inhibitory activities of the isolated metabolites (1-3, 9, and 10), their antibiofilm potentials against $S$. aureus, B. subtilis, E. coli, and P. aeruginosa were determined. Compounds 3 and 10 displayed potent antibiofilm activity against $P$. aeruginosa with \% inhibition rates of $94 \%$ and $73 \%$, respectively, while compounds 1, 2, and 9 showed mild to moderate inhibitory activity against E. coli with \% inhibition ranges of 34-54\%. Compounds 1 and 2 both showed potent to moderate inhibitory activity against $S$. aureus with \% inhibition rates of $50 \%$ and $75 \%$, respectively (Table 2 ). Similar to the antibacterial results, the presence of carboxylic acids on both C-1 and C-6 of the phenazine ring system decreased the antibiofilm effect towards Gram-negative strains, but made these derivatives active against Gram-positive ones, particularly, S. aureus (Figure 4).

\subsubsection{Cytotoxic Activity}

The five induced compounds (1-3, 9, and 10) were additionally tested for their cytotoxic activity against four human cancer cell lines (Table 3). Only compound 9 was able to induce moderate cytotoxicity towards the tested cell lines, with $\mathrm{IC}_{50}$ values ranging from 10 to $36 \mu \mathrm{M}$. Regarding the activity of phenazine derivatives (1-3), compound 2 was found to be the most active against all tested 
cell lines. Previous studies have suggested that phenazine-related compounds can exert significant cytotoxic activities through the inhibition of topoisomerase enzymes [28-30].

Table 2. Antibiofilm activity of $\mathbf{1 - 3 , 9}$, and $\mathbf{1 0}$ at $2 \mu \mathrm{M}$ against different bacterial strains.

\begin{tabular}{ccccc}
\hline Tested Compounds & S. aureus & B. subtilis & E. coli & P. aeruginosa \\
\hline $\mathbf{1}$ & $50.26 \pm 0.4$ & $12.10 \pm 3.2$ & $36.66 \pm 2.9$ & $18.36 \pm 0.9$ \\
$\mathbf{2}$ & $75.10 \pm 2.4$ & $18.65 \pm 1.6$ & $54.07 \pm 2.5$ & $22.28 \pm 1.5$ \\
$\mathbf{3}$ & $\mathrm{NA}$ & $\mathrm{NA}$ & $54.67 \pm 1.4$ & $93.98 \pm 2.2$ \\
$\mathbf{9}$ & $11.47 \pm 2.9$ & $4.91 \pm 1.8$ & $34.55 \pm 2.6$ & $7.39 \pm 1.9$ \\
$\mathbf{1 0}$ & $61.20 \pm 3.7$ & $20.29 \pm 1.1$ & $57.47 \pm 3.1$ & $73.52 \pm 1.3$ \\
\hline
\end{tabular}

NA: no activity.

Table 3. Cytotoxic activity of isolated compounds $1-3,9$, and 10 at $2 \mu \mathrm{M}$.

\begin{tabular}{ccccc}
\hline Tested Compounds & WI38 & HCT116 & HePG-2 & MCF7 \\
\hline $\mathbf{1}$ & $63.18 \pm 3.6$ & $85.04 \pm 3.9$ & $92.06 \pm 4.7$ & $>100$ \\
$\mathbf{2}$ & $76.30 \pm 3.9$ & $60.81 \pm 3.5$ & $76.11 \pm 3.9$ & $82.24 \pm 4.4$ \\
$\mathbf{3}$ & $51.22 \pm 3.2$ & $91.27 \pm 4.6$ & $>100$ & $>100$ \\
$\mathbf{9}$ & $36.47 \pm 2.3$ & $14.56 \pm 1.2$ & $10.16 \pm 0.9$ & $12.65 \pm 1.1$ \\
$\mathbf{1 0}$ & $>100$ & $>100$ & $>100$ & $>100$ \\
Doxorubicin & $6.72 \pm 0.5$ & $5.23 \pm 0.3$ & $4.50 \pm 0.2$ & $4.17 \pm 0.2$ \\
\hline
\end{tabular}

\subsubsection{In Vitro Enzyme Assay}

DNA gyrase is a topoisomerase-type enzyme present exclusively in bacterial cells. Inhibition of its subunit A (Gyr-A) leads to cell death by trapping the gyrase-DNA complex and preventing DNA replication. On the other hand, inhibition of Gyr-B blocks ATPase activity and thus deprives the cell of the energy source needed for DNA replication [31]. Gyr-B as a molecular target offers an opportunity to avoid cross-resistance to the well-known Gyr-A inhibitors, quinolones. Several phenazine and acridine derivatives have been reported to be topoisomerase I and II inhibitors in human cancer cells [28-30]. The characteristic planar structure of this class of compounds directs them to interact with the ATP-binding domains of the enzymes (ATPase pocket) [28]. On the other hand, PK is known to be a critical enzyme in catalyzing the final step of glycolysis, which involves the transfer of a phosphoryl group from phosphoenolpyruvate to ADP, producing pyruvate and ATP [32]. Recently, it was identified as a "superhub", listed among the top $1 \%$ of all interacting proteins in $S$. aureus and found to be a key regulator of the quorum-sensing system and the biofilm formation process in staphylococci [33-35]. Considering these points together with the structural similarity of our compounds (1-3) to previously well-known topoisomerase inhibitors, we selected Staphylococcus DNA gyrase-B and PK as possible molecular targets to mediate the observed antibacterial and antibiofilm activities of the induced phenazine derivatives toward S. aureus. In vitro studies (Table 4) showed 1 to be the most active compound against both Gyr-B and PK, followed by 2 and 3 . These finding indicate a direct link between the substitutions on C-1 and C-6 and the Gyr-B- and PK-inhibitory activities of this class of metabolites (Figure 3). Although the enzyme-inhibitory activity of compounds 1-3 was convergent, and compound $\mathbf{1}$ was slightly more active than compound $\mathbf{2}$ in the enzyme assay studies, compound $\mathbf{3}$ was inactive, and $\mathbf{1}$ was less active than $\mathbf{2}$ in both inhibitory assays against S. aureus. These observations could be attributed to the bacterial cell wall permeability, where $S$. aureus may permit the diffusion of $\mathbf{2}$ more easily than $\mathbf{1}$ and prevent the crossing of compound $\mathbf{1}$. In the same manner, $P$. aeruginosa's outer membrane may be selective only for compound 3 , and hence make both other phenazines (1 and 2) inactive. According to a previous report [36], small, moderately lipophilic compounds can cross the Gram-positive bacterial membrane more easily. In contrast, Gram-negative bacteria, which have porins (hydrophilic channels) in their outer membranes, are more selective for hydrophilic compounds. The calculated $\log P(\mathrm{cLogP})$ of each compound revealed that compound 2 had the optimum lipophilicity ( $\log P=1.9)$, whereas compound 1 was less lipophilic $(\mathrm{cLog} P=1.12)$ and compound 3 was more lipophilic $(\mathrm{cLog} P=2.97)$ Such differences in lipophilicity 
between compounds 1 to 3 could explain the opposite observations between enzyme inhibition and antibacterial and antibiofilm activities of compounds 1-3.

Table 4. Calculated interactions and affinities of compounds 1-3 with active-site residues of the Staphylococcus Gyr-B and PK.

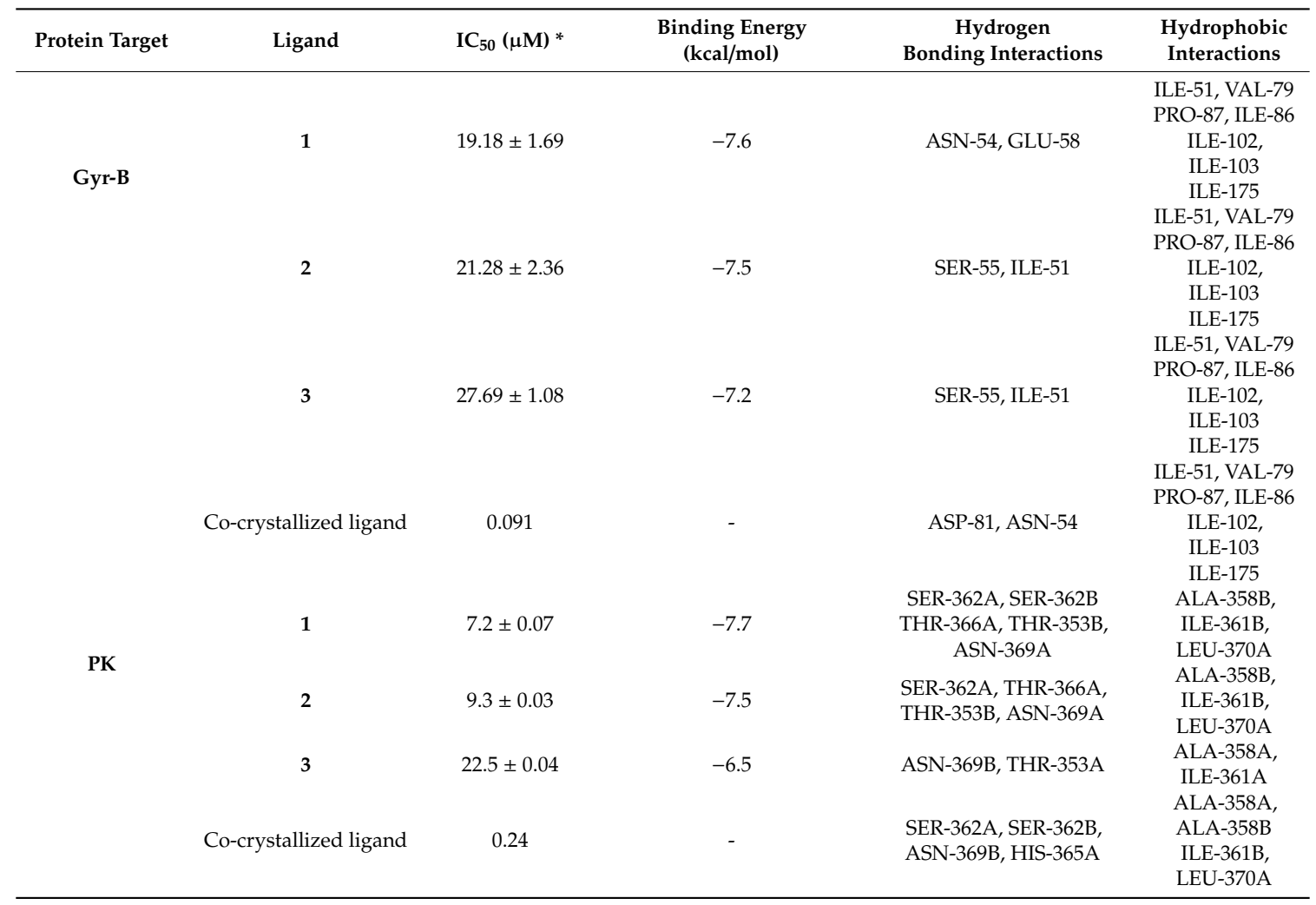

$* \mathrm{IC}_{50} \pm \mathrm{SD}(\mu \mathrm{M})$.

\subsection{Docking Study}

The potential binding modes of 1-3 with DNA Gyr-B and pyruvate kinase were investigated by docking at their active binding sites. Staphylococcus Gyr-B and PK of PDB code (3g7b and 3T0T) were selected for docking tests since they had optimum resolutions ( $2.3 \AA$ and $3.1 \AA$ ) and are co-crystallized with their inhibitors. The spheres surrounding the co-crystallized inhibitors were selected as active sites for docking. All isolated compounds exhibited convergent docking poses (Figure 5) and were comparable to the co-crystallized Gyr-B inhibitor [37]. The oxygens of both ester groups of $\mathbf{1}$ on $\mathrm{C} 1$ and C6 were hydrogen-bonded to ASN-54, similarly to the co-crystallized Gyr-B ligand, and GLU-58. These interactions meant that the whole molecule was well-embedded inside the active site pocket, where it was further stabilized by the hydrophobic interactions between the molecule's aromatic rings and ILE-51, VAL-79, PRO-87, ILE-86, ILE-102, ILE-103, and ILE-175. The absence of an ester group in 2 and 3 led them to take a different and less stable orientation inside the binding pocket and hence, their carboxylic acid moieties interacted from only one side with different amino acid residues via hydrogen bonds (SER-55 and ILE-51); however, they showed similar hydrophobic interactions to 1 . Unlike the co-crystallized Gyr-B inhibitor, 1-3 did not show any interactions with ASP-81. On the other hand, $\mathbf{1}$ and $\mathbf{2}$ showed similar binding modes in the PK active site, although different from that of 3 . The co-crystallized PK inhibitor [38] fitted perfectly inside the pocket formed between the enzyme's $A$ and $B$ subunits (Figure 6). This binding mode was stabilized by six main hydrogen bonds with SER-362A, SER-362B, ASN-369B, and HIS-365A (A and B notations correspond to PK subunits). These interacting residues are of particular interest as they are not conserved in human PK, and thus are likely to further influence the selectivity of the bacterial PK inhibitors. Herein, 1 showed a convergent binding 
mode to the co-crystallized PK inhibitor, where it anchored on one side of the PK active site (Figure 6) through three hydrogen bonds with SER-362A and SER-362B, similarly to the co-crystallized ligand, and through an additional hydrogen bond with THR-366A. All these interactions were from the ester moiety of one side of the molecule; the second ester group on the other side increased the molecular stability inside the binding site through hydrogen bonding to THR-353B and ASN-369A. Additionally, the aromatic planar structure of $\mathbf{1}$ was sandwiched between two hydrophobic surfaces inside the binding pocket, where it interacted via hydrophobic interactions with ALA-358B and ILE-361B from one side, and with LEU-370A from the other side. Regarding compound 2, it revealed a binding mode and interactions quite similar to that of $\mathbf{1}$. Such strong interactions with the PK binding side explain the good in vitro inhibitory activity of both $\mathbf{1}$ and $\mathbf{2}$ (Table 4 ) in comparison to $\mathbf{3}$, which showed different binding modes inside the enzyme's binding cavity. Unlike $\mathbf{1}$ and $\mathbf{2}$, and due to its single carboxylic acid moiety, 3 fitted inside the other corner of the active pocket through only three hydrogen bonds with ASN-369B and THR-353A. Regarding hydrophobic interactions, it interacted with only two residues, ALA-358A, and ILE-361A (Figure 6). These weaker interactions explain the inferior in vitro inhibitory activity of 3 toward PK (Table 4). In addition, it indicates the importance of the 1,6-dicarboxylic acid moieties in the future development of Staphylococcus PK inhibitors. 


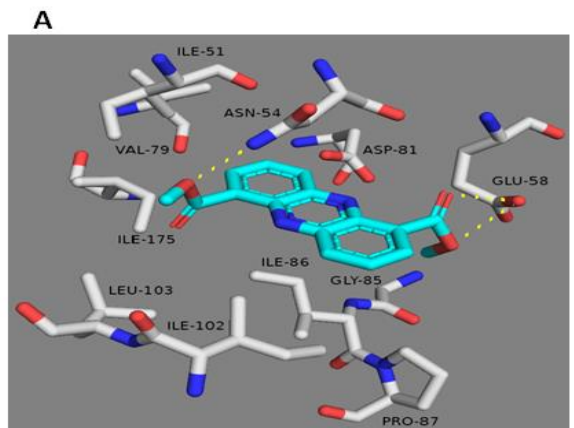

C

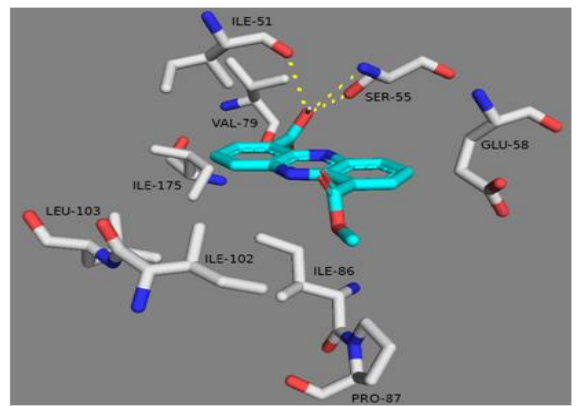

E

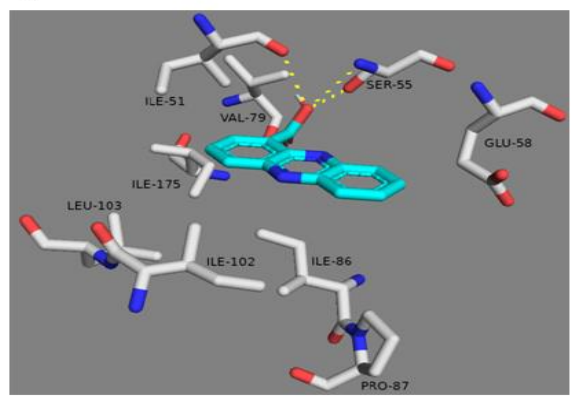

G

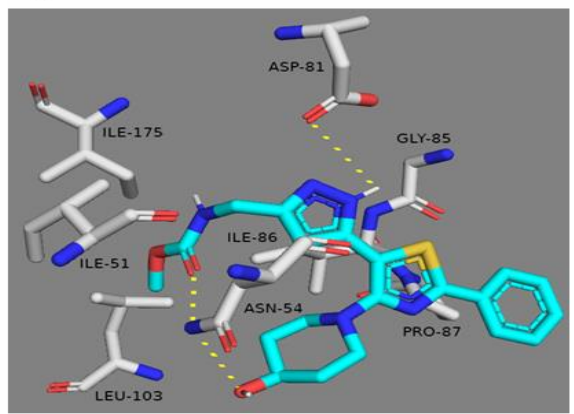

B

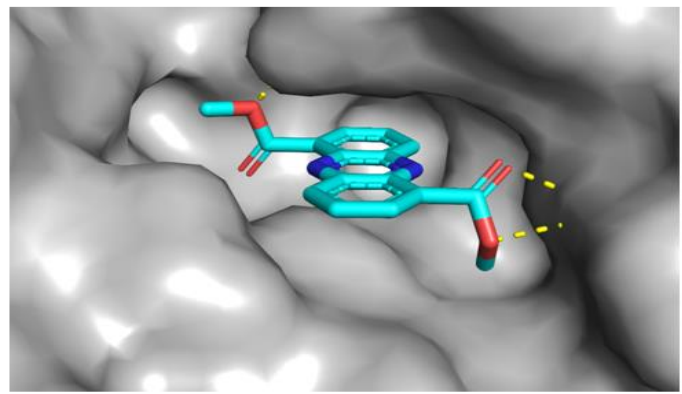

D

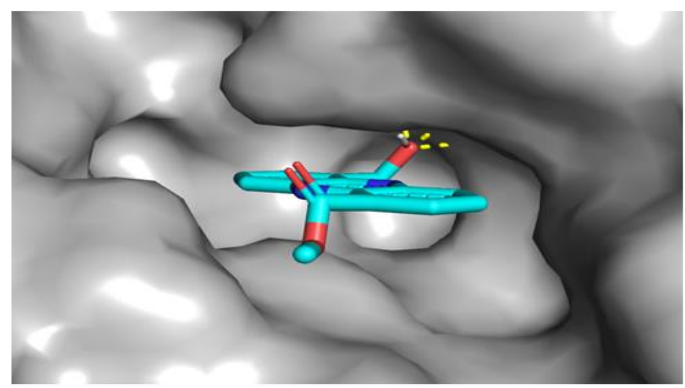

F

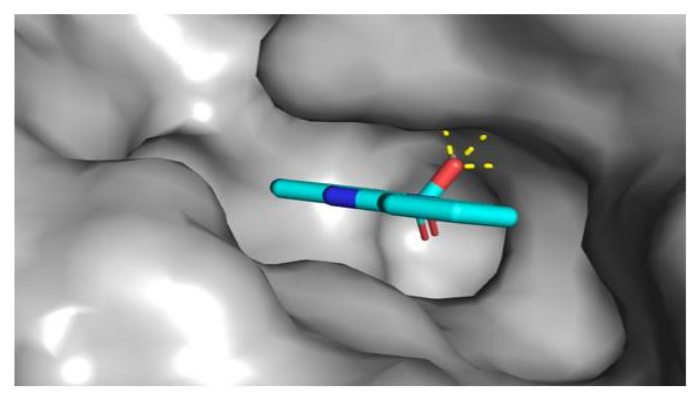

H

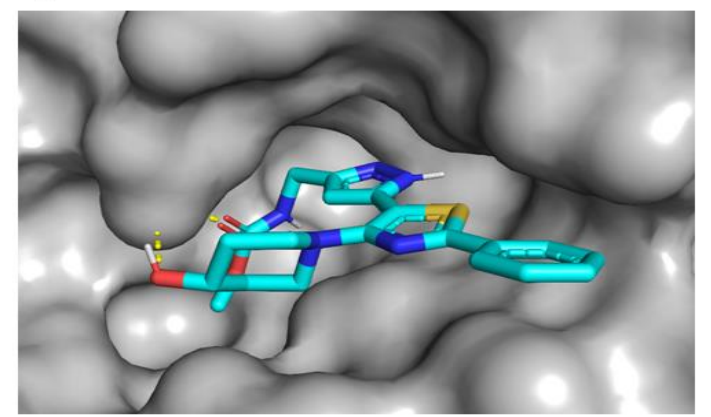

Figure 5. Docking of $\mathbf{1}(\mathbf{A}, \mathbf{B}), \mathbf{2}(\mathbf{C}, \mathbf{D})$ and $\mathbf{3}(\mathbf{E}, \mathbf{F})$ within the active site of Staphylococcal Gyr-B. (G,H) The key binding interactions of Gyr-B co-crystallized ligand. The amino acid side chains were depicted in $(\mathrm{A}, \mathrm{C}, \mathrm{E}, \mathrm{G})$ for clarification. 
A

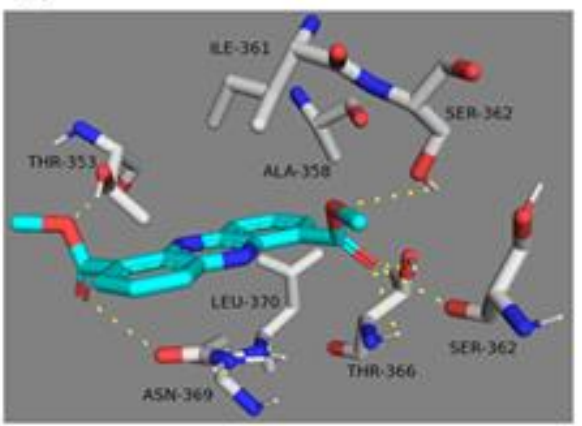

c

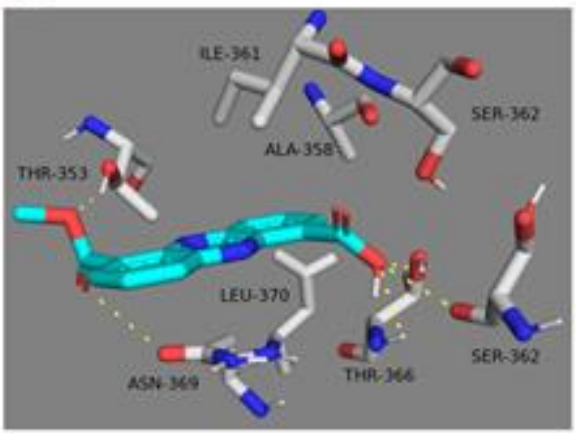

E

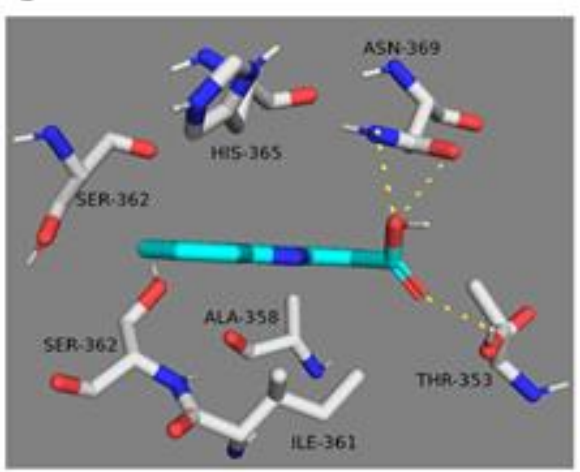

G

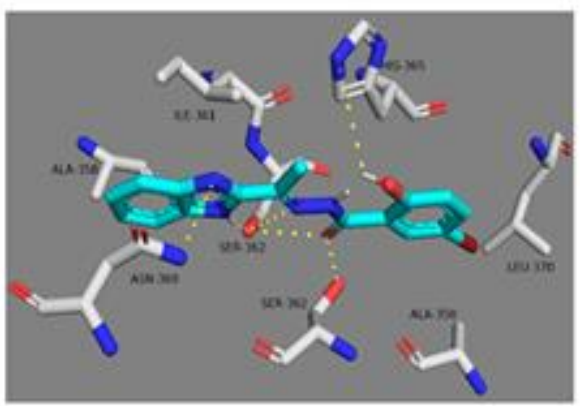

B

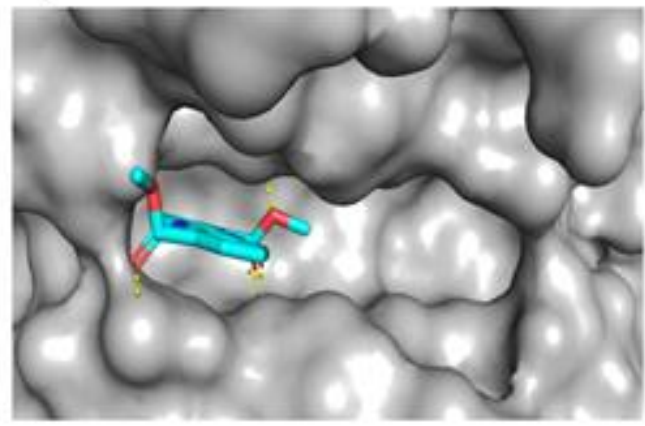

D

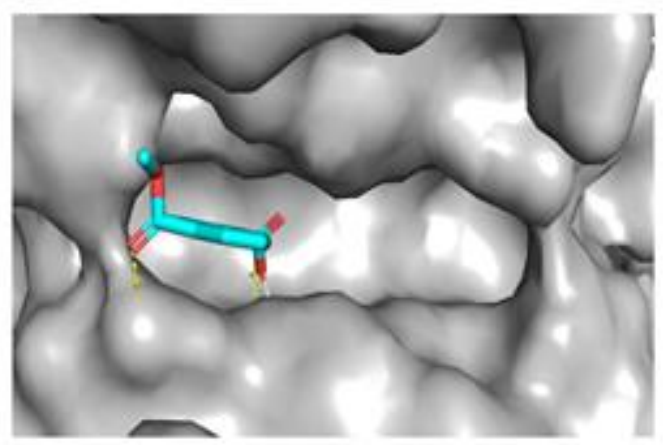

F

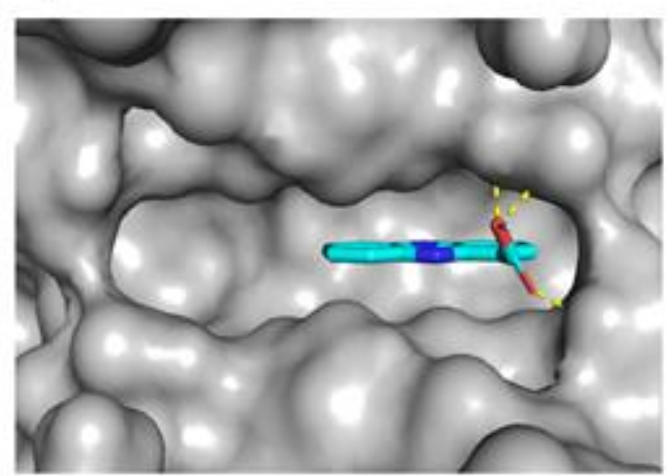

H

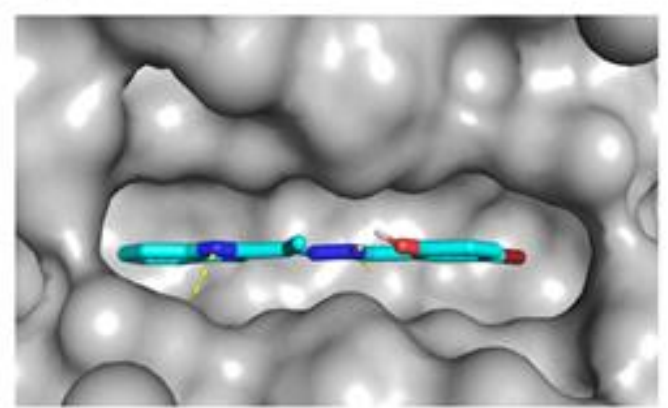

Figure 6. Docking of $\mathbf{1}(\mathbf{A}, \mathbf{B}), \mathbf{2}(\mathbf{C}, \mathbf{D})$, and $\mathbf{3}(\mathbf{E}, \mathbf{F})$ within the active site of Staphylococcus PK. $(\mathbf{G}, \mathbf{H})$ The key binding interactions of the Gyr-B co-crystallized ligand. The amino acid side chains are depicted in $(\mathrm{A}, \mathrm{C}, \mathrm{E}, \mathrm{G})$ for clarification.

\section{Material and Methods}

\subsection{General Experimental Procedures}

The chemical solvents used in this study, such as n-hexane, dichloromethane, ethyl acetate, and methanol, were obtained from Sigma-Aldrich, Saint Louis, Missouri, USA. Silica gel 60 (63-200 $\mu$ M, 
E. Merck, Sigma-Aldrich) and Sephadex LH20 (0.25-0.1 mm, GE Healthcare, Sigma-Aldrich) were used for chromatographic isolation and purification. Thin-layer chromatography was performed using pre-coated silica gel aluminum plates (E. Merck, Darmstadt, Germany, Kieselgel 60 F254, $20 \times 20 \mathrm{~cm}$, $0.25 \mathrm{~mm}) . p$-anisaldehyde $(0.5: 85: 10: 5$-anisaldehyde : methanol : glacial acetic acid : sulfuric acid) was used as visualizing spray reagent for different spots accompanied by heating at $110^{\circ} \mathrm{C} .1 \mathrm{D}, 2 \mathrm{D}$, and ${ }^{13} \mathrm{C}$ NMR spectra were recorded on a JEOL ECA-600 spectrometer $\left(600 \mathrm{MHz}\right.$ for ${ }^{1} \mathrm{H}$ and $150 \mathrm{MHz}$ for ${ }^{13} \mathrm{C}$, respectively). Each sample was dissolved in prober deuterated solvent such as $\mathrm{CDCl}_{3}$ and $\mathrm{CD}_{3} \mathrm{OD}$. All of the chemical shifts were recorded and expressed in ppm units related to the TMS signal as an internal standard, and coupling constants (J) were recorded in $\mathrm{Hz}$.

\subsection{Sponge Collection}

Callyspongia sp. and Spheciosponge vagabunda were collected from the Red Sea (Ras Mohamed, Sinai; (GPS coordinates $27^{\circ} 47.655 \mathrm{~N} ; 34^{\circ} 12.904 \mathrm{~W}$ ) at a depth of $10 \mathrm{~m}$ in August 2006. The collected sponges, identified by R.W.M. van Soest (University of Amsterdam, Netherlands), were transferred to plastic bags containing sterile seawater and transported to the laboratory. Sponge biomass was cleaned with sterile seawater, cut into fragments of ca. $1 \mathrm{~cm}^{3}$, and then carefully homogenized with 10 volumes of seawater. The freshly prepared supernatant was diluted in 10 -fold series $\left(10^{-1}, 10^{-2}, 10^{-3}\right)$ and subsequently plated out onto agar plates.

\subsection{Actinomycetes Isolation}

Different media were used for isolation of actinomycetes M1 [39]—ISP2 medium [40], oligotrophic medium [41], and marine agar [42]. The isolation of slow-growing actinomycetes needed all these different media to be supplemented with nalidixic acid $(25 \mu \mathrm{g} / \mathrm{mL})$, nystatin $(25 \mu \mathrm{g} / \mathrm{mL})$, and $0.2 \mu \mathrm{M}$ pore size filtered cycloheximide $(100 \mu \mathrm{g} / \mathrm{mL})$. Nystatin and cycloheximide prevent fungal growth, while nalidixic acid prevents many fast-growing Gram-negative bacteria [43]. All media consisted of Difco Bacto agar (18 g/L) and were prepared in $1 \mathrm{~L}$ artificial sterile sea water [44]. Micromonospora sp. UR56 and Actinokinospora sp. EG49 were cultivated on ISP2 medium. The inoculated agar plates were incubated at $30{ }^{\circ} \mathrm{C}$ for a long time, ranging from 6 to 8 weeks. Distinct colony morphotypes were selected and re-streaked many times until free of any contaminants.

\subsection{Molecular Identification}

16S rRNA gene amplification, cloning, and sequencing were performed using the universal primers 27F and 1492R according to Hentschel et al. [45]. Chimeric sequences were detected using the Pintail program [46]. The genus-level affiliation of the sequence was confirmed using the Ribosomal Database Project Classifier. The genus-level identification of all the sequences was performed using RDP Classifier (-g 16srrna, -f allrank) and confirmed with the SILVA Incremental Aligner (SINA) (search and classify option) [47]. An alignment was evaluated again using the SINA web aligner (variability profile: bacteria). Gap-only positions were removed with trimAL (-noallgaps). For phylogenetic tree construction, the best fitting model was first estimated using Model Generator. Visualization was performed using Interactive Tree of Life.

\subsection{Microbial Fermentation and Extract Preparation}

Micromonospora sp. UR 56 and Actinokineospora sp. EG49 were isolated from Red Sea sponges Callyspongia sp and Spheciospongia vagabunda, respectively. Each microbial strain was fermented in 10 Erlenmeyer flasks ( $2 \mathrm{~L}$ ), each containing $1 \mathrm{~L}$ of ISP2 medium and incubated at $30{ }^{\circ} \mathrm{C}$ with shaking (150 rpm) for 14 days. For the co-fermentation experiment, $10 \mathrm{~mL}$ of 5 day old culture of Micromonospora sp. UR56 was transferred into 10 Erlenmeyer flasks (2 L), each containing $1 \mathrm{~L}$ of ISP2 medium inoculated with $10 \mathrm{~mL}$ of 5 day old culture of Actinokineospora sp. EG49. After fermentation of axenic cultures and co-culture, filtration was performed, and the supernatant was extracted with ethyl acetate $(1.5 \mathrm{~L})$ to give the ethyl acetate soluble fraction $(700 \mathrm{mg})$. 


\subsection{LC-HR/MS Metabolomic Analysis}

LC-HR-ESI-MS metabolomics analyses were performed as previously described by Abdelmohsen et al. [48]. Ethyl acetate soluble fraction $1 \mathrm{mg} / \mathrm{mL}$ in $\mathrm{MeOH}$ was uploaded and analyzed using an Accela HPLC (Thermo Fisher Scientific, Karlsruhe, Germany) combined with UV-visible detector and Exactive-Orbitrap mass spectrometer (Thermo Fisher Scientific, Karlsruhe, Germany) using an HPLC column (an ACE C18, $75 \mathrm{~mm} \times 3.0 \mathrm{~mm}, 5 \mu \mathrm{M}$ column (Hichrom Limited, Reading, UK). The gradient elution was carried out at $300 \mu \mathrm{L} / \mathrm{min}$ for $30 \mathrm{~min}$ using purified water (A) and acetonitrile (B) with $0.1 \%$ formic acid in each mobile phase. The gradient program started with $10 \% \mathrm{~B}$, increased gradually to $100 \% \mathrm{~B}$, and continued isocratic for $5 \mathrm{~min}$ before linearly decreasing back to $10 \% \mathrm{~B}$ for $1 \mathrm{~min}$. The total analysis period for each fraction was $45 \mathrm{~min}$. The injection volume was $10 \mu \mathrm{L}$ and the column temperature was maintained at $20^{\circ} \mathrm{C}$. High-resolution mass spectrometry was performed in both negative and positive ionization modes with a spray voltage of $4.5 \mathrm{kV}$ and capillary temperature of $320^{\circ} \mathrm{C}$. The mass range was maintained at $150-1500 \mathrm{~m} / \mathrm{z}$. All positive and negative ionization files used to cover the highest number of metabolites were subjected to data mining software MZmine 2.10 (Okinawa Institute of Science and Technology Graduate University, Japan) for deconvolution, peak picking, alignment, deisotoping, and molecular formula prediction. Dictionary of natural products (DNP), Marinlit, and METLIN databases were used for identification of all metabolites.

\subsection{Isolation and Purification of Induced Metabolites}

The crude ethyl acetate (EtOAc) soluble fraction $(700 \mathrm{mg}$, obtained from co-fermentation) was chromatographed on a Sephadex LH20 $(32-64 \mu \mathrm{M}, 100 \times 25 \mathrm{~mm})$ column using $\mathrm{MeOH} / \mathrm{H}_{2} \mathrm{O}(80$ : $20 \%)$ to afford five main fractions (Fr.1 - Fr.5). Fr.2 (200 mg) was chromatographed over a silica gel column (CC). Gradient elution was performed using a gradient mixture of DCM : EtOAc (100: 0 to 0 : 100) followed by $100 \% \mathrm{MeOH}$ to afford 13 subfractions. SubFr.5 (30 mg) was further chromatographed on a Sephadex LH20 using Hex: DCM (50:50) as mobile phase to yield compound 3 (15 mg, 2.14\% crude weight). SubFr.7 was washed several times with DCM, resulting in crystallization and affording compound 9 (10 mg, 1.42\% crude weight). Fr.3 (175 mg) was chromatographed over a silica gel column with $n$-hexane: EtOAc (100:0 to 0:100) to yield nine subfractions (Fr.3-1 to Fr.3-9). Fr.3-7 and Fr.3-8 (30 mg and $20 \mathrm{mg}$ ) were further chromatographed over Sephadex LH20 using Hex: $\mathrm{CH}_{2} \mathrm{CL}_{2}$ (50:50) as mobile phase to afford pure compounds 1 and $\mathbf{2}$ (12 $\mathrm{mg}$ and $15 \mathrm{mg}, 1.71$ and $2.14 \%$ crude weight), respectively. Fr.5 $(75 \mathrm{mg})$ was further chromatographed on a Sephadex LH20 using MeOH as mobile phase to afford pure compound 10 (8 $\mathrm{mg}, 1.14 \%$ crude weight).

\subsection{Assessment of Antibacterial Activity}

The antibacterial activity of all isolated pure compounds (1-3, 9, and 10) was evaluated on Gram-positive pathogenic bacteria such as Bacillus subtilis (ATCC29212) and Staphylococcus aureus (ATCC9144 (and Gram-negative pathogenic bacteria such as Escherichia coli. (ATCC25922) and Pseudomonas aeruginosa (ATCC27853), as previously reported [49]. The tests were carried out in 96 well flat polystyrene plates. First, $10 \mu \mathrm{L}$ of each isolated compound $(15 \mu \mathrm{M})$ was transferred to $80 \mu \mathrm{L}$ of lysogeny broth followed by the addition of $10 \mu \mathrm{L}$ of bacterial suspension at log phase, and then all inoculated plates were incubated overnight at $37^{\circ} \mathrm{C}$. After incubation, the positive effect of the tested compounds was detected as clearance in the wells, and in compounds that showed no activity on the bacteria, the growth medium in the wells seemed opaque. The absorbance was observed after $20 \mathrm{~h}$ at OD600 in a Spectrostar Nano Microplate Reader (BMG LABTECH GmbH, Allmendgrun, Germany). The positive control was pathogenic bacteria plus distilled water, while the negative control was growth medium plus distilled water. 


\subsection{Assessment of Antibiofilm Activity}

The biofilm-inhibitory activities of the isolated pure compounds (1-3, 9, and 10) were measured using 96 well flat polystyrene plates against four clinical microbes comprising Gram-positive (Bacillus subtilis and Staphylococcus aureus) and Gram-negative (Escherichia coli and Pseudomonas aeruginosa) pathogenic bacteria, according to Antunes, et al. [50] with some modifications. Briefly, each well was filled with $180 \mu \mathrm{L}$ lysogeny broth (LB broth) and then inoculated with $10 \mu \mathrm{L}$ of pathogenic bacteria followed by addition of $10 \mu \mathrm{L}$ of sample $(2 \mu \mathrm{M})$ along with control (without test sample). All inoculated plates were then incubated overnight at $37^{\circ} \mathrm{C}$ and, after incubation, content in the wells was removed and wells were rinsed with $200 \mu \mathrm{L}$ of phosphate-buffered saline (PBS) $\mathrm{pH} 7.2$ to eliminate free-floating microbes and left to dry under sterilized laminar flow for $1 \mathrm{~h}$. For staining, $200 \mu \mathrm{L} /$ well of crystal violet $(0.1 \%$, w/v) was added, left for $1 \mathrm{~h}$, and then excessive stain was removed and plates retained for drying. Further, dried plates were rinsed with $95 \%$ ethanol and optical density was measured at $570 \mathrm{~nm}$ using a Spectrostar Nano Microplate Reader (BMG LABTECH $\mathrm{GmbH}$, Allmendgrun, Germany).

\subsection{Assessment of Cytotoxic Activity}

\section{MTT Assay}

This assay was performed using different human cancer cell lines, including mammary gland breast cancer (MCF-7), colorectal carcinoma (HCT-116), human lung cancer cell line (WI38), and hepatocellular carcinoma (HePG-2). The cell lines were purchased from ATCC by (VACSERA), Cairo, Egypt. Doxorubicin was used as a positive control drug. The cell lines were used to detect the inhibitory effects of isolated compounds on cell growth. Cell viability was determined via colorimetric assay (MTT), which is based on the transformation of the yellow tetrazolium bromide to a purple formazan by mitochondrial succinate dehydrogenase. Cell lines were cultivated in rpmI-1640 medium supplemented with $10 \%$ fetal bovine serum, 100 units $/ \mathrm{mL}$ penicillin, and $100 \mu \mathrm{g} / \mathrm{mL}$ streptomycin incubated at $37^{\circ} \mathrm{C}$ under $5 \% \mathrm{CO}_{2}$. The cell lines were plated in a 96 well microtiter plate at a concentration of $1.0 \times 10^{4}$ cells/well and incubated at $37^{\circ} \mathrm{C}$ under $5 \% \mathrm{CO}_{2}$ for 2 days. Subsequently, the cells were mixed with different concentrations of the isolated compounds and incubated for a further $24 \mathrm{~h}$, and then treated with $20 \mu \mathrm{L}$ of MTT solution at a concentration of $5 \mathrm{mg} / \mathrm{mL}$ and incubated for $4 \mathrm{~h}$. The purple formazan precipitates were dissolved in $100 \mu \mathrm{L}$ of dimethyl sulfoxide (DMSO) and the optical density for each well was measured and recorded at an absorbance of $570 \mathrm{~nm}$ using a plate reader (EXL 800, Biotek ${ }^{\circledR}$, Winooski, Vermont, USA). The relative cell viability as a percentage was calculated as A570 of treated samples/A570 of untreated sample $\times 100$.

\subsection{Enzyme Assays}

DNA gyrase (type II topoisomerase) and topoisomerase IV (ParE) add negative supercoils into DNA using ATP hydrolysis as a source of energy. They are considered crucial bacterial enzymes that are absent in eukaryotes. DNA-gyrase-B- and ParE-inhibitory activities were evaluated using the Inspiralis assay kit (Inspiralis ${ }^{\circledR}$, London, UK) on streptavidin-coated 96 well microtiter plates (Thermo Scientific, Hamburg, Germany), according to the manufacturer's protocol [51]. The assay detects the ability of the isolated compounds to prevent the ATPase activity of both gyrase-B and ParE subunits. On the other hand, pyruvate kinase (PK) has been discovered to be an important hub protein in the interactome of MRSA [52]. The PK-inhibitory activity of the isolated compounds was assessed according to a previously reported method [53].

\subsection{Docking Analysis}

Staphylococcus Gyr-B and PK crystal structures with the of PDB codes 3g7b and 3T0T, respectively, were used. Docking experiments were performed using AutoDock Vina docking software [54]. Such docking engines deal with the receptor as a rigid structure and the ligand as a flexible structure 
during their calculations. The co-crystallized ligands were utilized to assign the binding sites. The ligand-to-binding-site shape-matching root mean square threshold was set to $2.0 \AA$. The interaction energies were determined using the Charmm force field (CFF) (v.1.02) with $10.0 \AA$ as a non-bonded cutoff distance and distance-dependent dielectric. Subsequently, $5.0 \AA$ was set as an energy grid extending from the binding site. The tested compounds were energy-minimized inside the selected binding pocket. The editing and visualization of the generated binding poses were performed using Pymol 2.3 software (Schrödinger, München, Germany).

\subsection{Structuraal Elucidation of Isolated Compounds 1-3, 9, and 10.}

The structures of the known induced metabolites were confirmed by comparison of their spectroscopic (HRMS and ${ }^{1} \mathrm{H},{ }^{13} \mathrm{C}$ and 2D-NMR) data with the published literature data as 1, dimethylphenazine-1,6-dicarboxylate [55]; 2, phencomycin [55-57]; 3, tubermycinB [57-60]; 9, N-(2-hydroxyphenyl)-acetamide [24,56]; and 10, $p$-anisamide [61].

\section{Conclusions}

Actinomycetes genomes, in particular the order Actinomycetales, consist of numerous biosynthetic gene clusters encoding for secondary metabolites that have not yet been detected under standard laboratory conditions, and that need to be cultivated using elicitation approaches such as co-cultivation. In the present work, two Red-Sea-sponge-associated actinomycetes, Micromonospora sp. UR56 and Actinokineospora sp. EG49, were subjected to co-cultivation. Metabolomic profiling of both axenic actinomycetes and their co-culture revealed that the latter was more diverse in its induced metabolites profile, particularly in terms of phenazine derivatives. After isolation of the major induced metabolites (1-3, 9, and 10), their possible antibacterial, antibiofilm, and cytotoxic activities were assessed. Phenazine derivatives 1-3 were significantly active as antibacterial and antibiofilm agents with mild cytotoxicity. Subsequently, they were tested against Gyr-B and PK as possible molecular targets. The presence of carboxylic acid or an ester moiety at C-1 and C- 6 was found to be crucial for the activity spectra of these compounds, where the antibacterial and antibiofilm effects were flipped from Gram-positive to Gram-negative strains, and their enzyme-inhibitory activities were significantly decreased upon removal of either carboxylic acid or the ester moiety at C-6. These findings could represent a good starting point from which to develop further phenazine-based antibiotics. Additionally, they highlight microbial mixed fermentation as a simple and effective approach to produce new antimicrobial agents through the induction of otherwise cryptic bacterial biogenetic pathways.

Supplementary Materials: The following are available online at http://www.mdpi.com/1660-3397/18/5/243/s1, Tables S1-S3: The dereplication results of the ethyl acetate fraction of micromonospora UR 56, Figures S1-S29: 1D and 2D NMR spectra of isolated compounds, Figures S30-S32: Dereplicated metabolites from metabolomic analysis.

Author Contributions: Conceptualization, M.S.H., R.M., H.M.H., A.M.S., M.E.R. and M.M.F.; methodology, M.M.F. and A.M.S.; data curation, A.A.H., H.M.H., U.R.A., M.E.R., A.M.S., H.A.A. and S.F.A.; original draft preparation, M.M.F.; writing, review and editing, all authors. All authors have read and agreed to the published version of the manuscript.

Funding: This research received no external funding.

Conflicts of Interest: The authors declare there is no conflict of interest.

\section{References}

1. Pettit, R.K. Mixed fermentation for natural product drug discovery. Appl. Microbiol. Biotechnol. 2009, 83, 19-25. [CrossRef] [PubMed]

2. Engelhardt, K.; Degnes, K.F.; Kemmler, M.; Bredholt, H.; Fjærvik, E.; Klinkenberg, G.; Sletta, H.; Ellingsen, T.E.; Zotchev, S.B. Production of a new thiopeptide antibiotic, TP-1161, by a marine Nocardiopsis species. Appl. Environ. Microbiol. 2010, 76, 4969-4976. [CrossRef] [PubMed]

3. Olano, C.; Méndez, C.; Salas, J.A. Antitumor compounds from marine actinomycetes. Mar. Drugs 2009, 7, 210-248. [CrossRef] [PubMed] 
4. Pimentel-Elardo, S.M.; Kozytska, S.; Bugni, T.S.; Ireland, C.M.; Moll, H.; Hentschel, U. Anti-parasitic compounds from Streptomyces sp. strains isolated from Mediterranean sponges. Mar. Drugs 2010, 8, 373-380. [CrossRef]

5. Abdelmohsen, U.R.; Szesny, M.; Othman, E.M.; Schirmeister, T.; Grond, S.; Stopper, H.; Hentschel, U. Antioxidant and anti-protease activities of diazepinomicin from the sponge-associated Micromonospora strain RV115. Mar. Drugs 2012, 10, 2208-2221. [CrossRef]

6. Wolfender, J.-L.; Marti, G.; Ferreira Queiroz, E. Advances in techniques for profiling crude extracts and for the rapid identificationof natural products: Dereplication, quality control and metabolomics. Curr. Org. Chem. 2010, 14, 1808-1832. [CrossRef]

7. Wang, J.; Lin, W.; Wray, V.; Lai, D.; Proksch, P. Induced production of depsipeptides by co-culturing Fusarium tricinctum and Fusarium begoniae. Tetrahedron Lett. 2013, 54, 2492-2496. [CrossRef]

8. Nett, M.; Ikeda, H.; Moore, B.S. Genomic basis for natural product biosynthetic diversity in the actinomycetes. Nat. Prod. Rep. 2009, 26, 1362-1384. [CrossRef]

9. Winter, J.M.; Behnken, S.; Hertweck, C. Genomics-inspired discovery of natural products. Curr. Opin. Chem. Biol. 2011, 15, 22-31. [CrossRef]

10. Oh, D.-C.; Jensen, P.R.; Kauffman, C.A.; Fenical, W. Libertellenones A-D: Induction of cytotoxic diterpenoid biosynthesis by marine microbial competition. Bioorg. Med. Chem. 2005, 13, 5267-5273. [CrossRef]

11. Scherlach, K.; Hertweck, C. Triggering cryptic natural product biosynthesis in microorganisms. Org. Biomol. Chem. 2009, 7, 1753-1760. [CrossRef] [PubMed]

12. Schroeckh, V.; Scherlach, K.; Nützmann, H.-W.; Shelest, E.; Schmidt-Heck, W.; Schuemann, J.; Martin, K.; Hertweck, C.; Brakhage, A.A. Intimate bacterial-fungal interaction triggers biosynthesis of archetypal polyketides in Aspergillus nidulans. Proc. Natl. Acad. Sci. USA 2009, 106, 14558-14563. [CrossRef] [PubMed]

13. Chiang, Y.-M.; Chang, S.-L.; Oakley, B.R.; Wang, C.C.C. Recent advances in awakening silent biosynthetic gene clusters and linking orphan clusters to natural products in microorganisms. Curr. Opin. Chem. Biol. 2011, 15, 137-143. [CrossRef] [PubMed]

14. El-Hawary, S.S.; Sayed, A.M.; Mohammed, R.; Khanfar, M.; Rateb, M.E.; Mohammed, T.A.; Hajjar, D.; Hassan, H.M.; Gulder, T.A.M.; Abdelmohsen, U.R. New Pim-1 kinase inhibitor from the co-culture of two sponge-associated actinomycetes. Front. Chem. 2018, 6, 538. [CrossRef]

15. Cueto, M.; Jensen, P.R.; Kauffman, C.; Fenical, W.; Lobkovsky, E.; Clardy, J. Pestalone, a new antibiotic produced by a marine fungus in response to bacterial challenge. J. Nat. Prod. 2001, 64, 1444-1446. [CrossRef]

16. Thissera, B.; Alhadrami, H.A.; Hassan, M.H.A.; Hassan, H.M.; Bawazeer, M.; Yaseen, M.; Belbahri, L.; Rateb, M.E.; Behery, F.A. Induction of cryptic antifungal pulicatin derivatives from Pantoea agglomerans by microbial co-culture. Biomolecules 2020, 10, 268. [CrossRef]

17. Oh, D.-C.; Kauffman, C.A.; Jensen, P.R.; Fenical, W. Induced production of emericellamides A and B from the marine-derived fungus Emericella sp. In competing co-culture. J. Nat. Prod. 2007, 70, 515-520. [CrossRef]

18. McDonald, M.; Mavrodi, D.V.; Thomashow, L.S.; Floss, H.G. Phenazine biosynthesis in Pseudomonas fluorescens: Branchpoint from the primary shikimate biosynthetic pathway and role of phenazine-1, 6-dicarboxylic Acid. J. Am. Chem. Soc. 2001, 123, 9459-9460. [CrossRef]

19. Liu, B.; Liu, K.; Lu, Y.; Zhang, D.; Yang, T.; Li, X.; Ma, C.; Zheng, M.; Wang, B.; Zhang, G. Systematic evaluation of structure-activity relationships of the riminophenazine class and discovery of a $\mathrm{C} 2$ pyridylamino series for the treatment of multidrug-resistant tuberculosis. Molecules 2012, 17, 4545-4559. [CrossRef]

20. Kunz, A.; Labes, A.; Wiese, J.; Bruhn, T.; Bringmann, G.; Imhoff, J. Nature's lab for derivatization: New and revised structures of a variety of streptophenazines produced by a sponge-derived Streptomyces strain. Mar. Drugs 2014, 12, 1699-1714. [CrossRef]

21. Reddy, V.M.; O'Sullivan, J.F.; Gangadharam, P.R.J. Antimycobacterial activities of riminophenazines. J. Antimicrob. Chemother. 1999, 43, 615-623. [CrossRef] [PubMed]

22. Mavrodi, D.V.; Blankenfeldt, W.; Thomashow, L.S. Phenazine compounds in fluorescent Pseudomonas spp. biosynthesis and regulation. Annu. Rev. Phytopathol. 2006, 44, 417-445. [CrossRef] [PubMed]

23. Spicer, J.A.; Gamage, S.A.; Rewcastle, G.W.; Finlay, G.J.; Bridewell, D.J.A.; Baguley, B.C.; Denny, W.A. Bis (phenazine-1-carboxamides): Structure- activity relationships for a new class of dual topoisomerase I/II-directed anticancer drugs. J. Med. Chem. 2000, 43, 1350-1358. [CrossRef] [PubMed] 
24. Dashti, Y.; Grkovic, T.; Abdelmohsen, U.R.; Hentschel, U.; Quinn, R.J. Production of induced secondary metabolites by a co-culture of sponge-associated actinomycetes, Actinokineospora sp. EG49 and Nocardiopsis sp. RV163. Mar. Drugs 2014, 12, 3046-3059. [CrossRef]

25. Boumehira, A.Z.; El-Enshasy, H.A.; Hacène, H.; Elsayed, E.A.; Aziz, R.; Park, E.Y. Recent progress on the development of antibiotics from the genus Micromonospora. Biotechnol. bioprocess Eng. 2016, 21, 199-223. [CrossRef]

26. Kuncharoen, N.; Kudo, T.; Ohkuma, M.; Tanasupawat, S. Micromonospora azadirachtae sp. nov., isolated from roots of Azadirachta indica A. Juss. var. siamensis Valeton. Antonie van Leeuwenhoek, Int. J. Gen. Mol. Microbiol. 2019, 112, 253-262. [CrossRef]

27. Borrero, N.V.; Bai, F.; Perez, C.; Duong, B.Q.; Rocca, J.R.; Jin, S.; Huigens, R.W., III. Phenazine antibiotic inspired discovery of potent bromophenazine antibacterial agents against Staphylococcus aureus and Staphylococcus epidermidis. Org. Biomol. Chem. 2014, 12, 881-886. [CrossRef]

28. Zhuo, S.-T.; Li, C.-Y.; Hu, M.-H.; Chen, S.-B.; Yao, P.-F.; Huang, S.-L.; Ou, T.-M.; Tan, J.-H.; An, L.-K.; Li, D. Synthesis and biological evaluation of benzo [a] phenazine derivatives as a dual inhibitor of topoisomerase I and II. Org. Biomol. Chem. 2013, 11, 3989-4005. [CrossRef]

29. Vicker, N.; Burgess, L.; Chuckowree, I.S.; Dodd, R.; Folkes, A.J.; Hardick, D.J.; Hancox, T.C.; Miller, W.; Milton, J.; Sohal, S. Novel angular benzophenazines: Dual topoisomerase I and topoisomerase II inhibitors as potential anticancer agents. J. Med. Chem. 2002, 45, 721-739. [CrossRef]

30. Adjei, A.A.; Charron, M.; Rowinsky, E.K.; Svingen, P.A.; Miller, J.; Reid, J.M.; Sebolt-Leopold, J.; Ames, M.M.; Kaufmann, S.H. Effect of pyrazoloacridine (NSC 366140) on DNA topoisomerases I and II. Clin. cancer Res. 1998, 4, 683-691.

31. Yi, L.; Lü, X. New strategy on antimicrobial-resistance: Inhibitors of DNA replication enzymes. Curr. Med. Chem. 2019, 26, 1761-1787. [CrossRef] [PubMed]

32. Zoraghi, R.; Worrall, L.; See, R.H.; Strangman, W.; Popplewell, W.L.; Gong, H. Methicillin-resistant Staphylococcus aureus (MRSA) pyruvate kinase as a target for bis-indole alkaloids with antibacterial activities. J. Biol. Chem. 2011, 286, 44716-44725. [CrossRef] [PubMed]

33. Ohlsen, K.; Donat, S. The impact of serine/threonine phosphorylation in Staphylococcus aureus. Int. J. Med. Microbiol. 2010, 300, 137-141. [CrossRef] [PubMed]

34. Vasu, D.; Sunitha, M.M.; Srikanth, L.; Swarupa, V.; Prasad, U.V.; Sireesha, K.; Yeswanth, S.; Kumar, P.S.; Venkatesh, K.; Chaudhary, A. In Staphylococcus aureus the regulation of pyruvate kinase activity by serine/threonine protein kinase favors biofilm formation. 3 Biotech 2015, 5, 505-512. [CrossRef] [PubMed]

35. Wang, J.; Jiao, H.; Meng, J.; Qiao, M.; Du, H.; He, M.; ming, K.; Liu, J.; Wang, D.; Wu, Y. Baicalin inhibits biofilm formation and the quorum-sensing system by regulating the MsrA drug efflux pump in Staphylococcus saprophyticus. Front. Microbiol. 2019, 10, 2800. [CrossRef]

36. Benedetto Tiz, D.; Kikelj, D.; Zidar, N. Overcoming problems of poor drug penetration into bacteria: Challenges and strategies for medicinal chemists. Expert Opin. Drug Discov. 2018, 13, 497-507. [CrossRef]

37. Ronkin, S.M.; Badia, M.; Bellon, S.; Grillot, A.-L.; Gross, C.H.; Grossman, T.H.; Mani, N.; Parsons, J.D.; Stamos, D.; Trudeau, M. Discovery of pyrazolthiazoles as novel and potent inhibitors of bacterial gyrase. Bioorg. Med. Chem. Lett. 2010, 20, 2828-2831. [CrossRef]

38. Axerio-Cilies, P.; See, R.H.; Zoraghi, R.; Worral, L.; Lian, T.; Stoynov, N.; Jiang, J.; Kaur, S.; Jackson, L.; Gong, H. Cheminformatics-driven discovery of selective, nanomolar inhibitors for staphylococcal pyruvate kinase. ACS Chem. Biol. 2011, 7, 350-359. [CrossRef]

39. Mincer, T.J.; Jensen, P.R.; Kauffman, C.A.; Fenical, W. Widespread and persistent populations of a major new marine actinomycete taxon in ocean sediments. Appl. Environ. Microbiol. 2002, 68, 5005-5011. [CrossRef]

40. Shirling, E.B.T.; Gottlieb, D. Methods for characterization of Streptomyces species. Int. J. Syst. Bacteriol. 1966, 16, 313-340. [CrossRef]

41. Olson, J.B.; Lord, C.C.; McCarthy, P.J. Improved recoverability of microbial colonies from marine sponge samples. Microb. Ecol. 2000, 40, 139-147. [CrossRef] [PubMed]

42. Weiner, R.M.; Segall, A.M.; Colwell, R.R. Characterization of a marine bacterium associated with Crassostrea virginica (the eastern oyster). Appl. Environ. Microbiol. 1985, 49, 83-90. [CrossRef] [PubMed]

43. Webster, N.S.; Wilson, K.J.; Blackall, L.L.; Hill, R.T. Phylogenetic diversity of bacteria associated with the marine sponge Rhopaloeides odorabile. Appl. Environ. Microbiol. 2001, 67, 434-444. [CrossRef] [PubMed]

44. Lyman, J.; Fleming, R.H. Composition of sea water. J. mar. Res 1940, 3, 134-146. 
45. Hentschel, U.; Hopke, J.; Horn, M.; Friedrich, A.B.; Wagner, M.; Hacker, J.; Moore, B.S. Molecular evidence for a uniform microbial community in sponges from different oceans. Appl. Environ. Microbiol. 2002, 68, 4431-4440. [CrossRef] [PubMed]

46. Ashelford, K.E.; Chuzhanova, N.A.; Fry, J.C.; Jones, A.J.; Weightman, A.J. At least 1 in 20 16S rRNA sequence records currently held in public repositories is estimated to contain substantial anomalies. Appl. Environ. Microbiol. 2005, 71, 7724-7736. [CrossRef]

47. Pruesse, E.; Peplies, J.; Glöckner, F.O. SINA: Accurate high-throughput multiple sequence alignment of ribosomal RNA genes. Bioinformatics 2012, 28, 1823-1829. [CrossRef]

48. Abdelmohsen, U.; Cheng, C.; Viegelmann, C.; Zhang, T.; Grkovic, T.; Ahmed, S.; Quinn, R.; Hentschel, U.; Edrada-Ebel, R. Dereplication strategies for targeted isolation of new antitrypanosomal actinosporins A and B from a marine sponge associated-Actinokineospora sp. EG49. Mar. Drugs 2014, 12, 1220-1244. [CrossRef]

49. Ingebrigtsen, R.A.; Hansen, E.; Andersen, J.H.; Eilertsen, H.C. Light and temperature effects on bioactivity in diatoms. J. Appl. Phycol. 2016, 28, 939-950. [CrossRef]

50. Antunes, A.L.S.; Trentin, D.S.; Bonfanti, J.W.; PINTO, C.C.F.; PEREZ, L.R.R.; Macedo, A.J.; Barth, A.L. Application of a feasible method for determination of biofilm antimicrobial susceptibility in staphylococci. Apmis 2010, 118, 873-877. [CrossRef]

51. Durcik, M.; Tammela, P.; Barančoková, M.; Tomašič, T.; Ilaš, J.; Kikelj, D.; Zidar, N. Synthesis and evaluation of N-phenylpyrrolamides as DNA gyrase B Inhibitors. ChemMedChem 2018, 13, 186-198. [CrossRef] [PubMed]

52. Suzuki, K.; Ito, S.; Shimizu-Ibuka, A.; Sakai, H. Crystal structure of pyruvate kinase from Geobacillus stearothermophilus. J. Biochem. 2008, 144, 305-312. [CrossRef] [PubMed]

53. El-Sayed, M.T.; Zoraghi, R.; Reiner, N.; Suzen, S.; Ohlsen, K.; Lalk, M.; Altanlar, N.; Hilgeroth, A. Novel inhibitors of the methicillin-resistant Staphylococcus aureus (MRSA)-pyruvate kinase. J. Enzyme Inhib. Med. Chem. 2016, 31, 1666-1671. [CrossRef] [PubMed]

54. Sayed, A.M.; Alhadrami, H.A.; El-Hawary, S.S.; Mohammed, R.; Hassan, H.M.; Rateb, M.E.; Abdelmohsen, U.R.; Bakeer, W. Discovery of two brominated oxindole alkaloids as Staphylococcal DNA gyrase and pyruvate kinase inhibitors via inverse virtual screening. Microorganisms 2020, 8, 293. [CrossRef] [PubMed]

55. Chatterjee, S.; Vijayakumar, E.K.S.; Franco, C.M.M.; Maurya, R.; Blumbach, J.; Ganguli, B.N. Phencomycin, a new antibiotic from a Streptomyces species HIL Y-9031725. J. Antibiot. (Tokyo). 1995, 48, 1353-1354. [CrossRef]

56. Pusecker, K.; Laatsch, H.; Helmke, E.; Weyland, H. Dihydrophencomycin methyl ester, a new phenazine derivative from a marine streptomycete. J. Antibiot. (Tokyo). 1997, 50, 479-483. [CrossRef]

57. Cheng, C.; Othman, E.M.; Fekete, A.; Krischke, M.; Stopper, H.; Edrada-Ebel, R.A.; Mueller, M.J.; Hentschel, U.; Abdelmohsen, U.R. Strepoxazine A, a new cytotoxic phenoxazin from the marine sponge-derived bacterium Streptomyces sp. SBT345. Tetrahedron Lett. 2016, 57, 4196-4199. Available online: http://dx.doi.org/10.1016/j. tetlet.2016.08.005. [CrossRef]

58. Geiger, A.; Keller-Schierlein, W.; Brandl, M.; Zahner, H. Metabolites of microorganisms. 247 phenazines from Streptomyces antibioticus, strain Tü 2706. J. Antibiot. 1988, 41, 1542-1551. [CrossRef]

59. Gebhardt, K.; Schimana, J.; Krastel, P.; Dettner, K.; Rheinheimer, J.; Zeeck, A.; Fiedler, H.-P. Endophenazines $\mathrm{AD}$, new phenazine antibiotics from the Arthropod associated endosymbiont Streptomyces anulatus. J. Antibiot. 2002, 55, 794-800. [CrossRef]

60. Lee, H.-S.; Kang, J.S.; Choi, B.-K.; Lee, H.-S.; Lee, Y.-J.; Lee, J.; Shin, H.J. Phenazine derivatives with anti-inflammatory activity from the deep-sea sediment-derived yeast-like fungus Cystobasidium laryngis IV17-028. Mar. Drugs. 2019, 17, 482. [CrossRef]

61. National Center for Biotechnology Information.pub Chemdatabase. 4-Methoxy Benzamide. Available online: https://pubchem.ncbi.nlm.nih.gov/compound/4-Methoxybenzamide (accessed on 15 April 2020).

(C) 2020 by the authors. Licensee MDPI, Basel, Switzerland. This article is an open access article distributed under the terms and conditions of the Creative Commons Attribution (CC BY) license (http://creativecommons.org/licenses/by/4.0/). 